\title{
Etnoekologi Masyarakat Samin Kudus Jawa Tengah
}

\author{
Jumari $^{1)}$, Dede Setiadi ${ }^{2)}$, Y.Purwanto ${ }^{3)}$ dan Edi Guhardja ${ }^{2)}$ \\ 1) Laboratorium Ekologi dan Biosistematik Jurusan Biologi FSM Undip \\ email: jumari_bot07@yahoo.com \\ ${ }^{2)}$ Dept. Biologi FMIPA IPB \\ ${ }^{3)}$ Bidang Botani, Pusat Penelitian Biologi-LIPI
}

\begin{abstract}
Abstrak
Penelitian Etnoekologi Masyarakat Samin di Kudus telah dilaksanakan pada bulan Maret 2011 hingga Agustus 2011. Tujuan penelitian ini adalah untuk mengkaji dan mendokumentasi pengetahuan lokal Masyarakat Samin Kudus mengenai pandangan masyarakat terhadap lingkungannya. Lokasi penelitian di desa Larikrejo dan desa Kaliyoso, Kecamatan Undaan, Kabupaten Kudus. Teknik pengambilan data dilakukan dengan pengamatan langsung di lapangan, wawancara terbuka (open ended), wawancara terstruktur dan semi terstruktur terhadap informan kunci; dan kelompok diskusi terfokus (Focus Group discussion, FGD). Pengelolaan sumberdaya lokal di lingkungan masyarakat samin digambarkan secara diskribtif fenomenologi. Pengetahuan tradisional masyarakat tentang lingkungannya tergambar pada bentuk penggunaan lahan dan sistem pengelolaannya. Satuan lingkungan dan aktifitas produksi masyarakat berupa sawah, pekarangan, tegalan, rawa, embung dan sungai. Interaksi masyarakat Samin dengan lingkungannya sangat kuat, ibarat manusia dengan sandang pangan, atau ibarat hidup dengan penghidupannya. Pandangan masyarakat Samin terhadap kepentingan lahan mengalami perubahan seiring dengan perubahan kondisi lingkungan dan tingkat pengetahuan mereka.
\end{abstract}

Kata kunci : Etnoekologi, samin, fenomenologi

\begin{abstract}
The study of the ethnoecology of Samin Society in Kudus been conducted in March 2011 to August 2011. The aim of this study was to review and document local knowledge of of Samin Society about their views of the environment. The location is Larikrejo and Kaliyoso villages, Undaan District, Regency of Kudus. Data collection techniques with direct field observation, open interviews (open ended), structured interviews with key informants, and focus group discussions (FGD). Results of research on local resource management in communities samin illustrated on describtif phenomenology. Theirs traditional knowledge about the environment is reflected in the form of land use management systems. Environmental unit and production activities such as: rice fields, yards, dry field, swamps, embung and rivers. Samin community interaction with the environment is very strong, like wong (humans) with sandang pangan (food and clothing), or like living with a livelihood. Society's view of land interests change with the change of environmental conditions and their knowledge level.
\end{abstract}

Key word: Ethoecology, local knowledge, Samin Society, view of invironment, environmental unit

\section{PENDAHULUAN}

Dalam kehidupan manusia senantiasa terjadi hubungan timbal balik antara sistem sosial dengan sistem biofisik (ekosistem) (Rambo, 1983; Parson, 1985; Marten 2001). Kedua sistem berubah sesuai dengan dinamika internal masingmasing, namun tetap mempertahankan integritas sebagai sistem terpisah. Latar belakang sosial budaya dapat mempengaruhi perilaku manusia dalam memperlakukan alam lingkungannya. Sebaliknya karena pengaruh lingkungan biofisik, manusia harus melakukan penyesuaian diri terhadap lingkungan agar dapat bertahan hidup (Hutterer \& Rambo, 1985). Hubungan sistem sosial dan biofisik tersebut sangat dinamis setiap waktu. Perubahan sistem sosial masyarakat secara otomatis akan mengakibatkan perubahan sistem biofisik (Rambo, 1983).

Studi etnoekologi bertujuan untuk mengkaji pengetahuan lokal pengenai interaksi antara masyarakat lokal dengan lingkungannya. Pada saat ini pengetahuan tersebut mengalami 
degradasi dan banyak ditinggalkan oleh penduduk karena tergerus oleh kemajuan teknologi dan berbagai aktivitas manusia yang cenderung mengabaikan kelestarian lingkungan. Oleh karena itu sangat mendesak untuk dilakukan pendokumentasian dan pengkajian pengetahuan masyarakat tradisional termasuk pada Masyarakat Samin.

Masyarakat Samin adalah masyarakat tradisional di Jawa yang keberadaanya semakin terpinggirkan. Mereka mengharapkan keberadaan atau "kemerdekaan" mereka diakui agar dapat menjalankan sistem kehidupan sesuai ajaran yang mereka yakini. Profesi utama dan mereka adalah petani, maka ketergantungan terhadap sumberdaya alam sangat tinggi. Keterbatasan lahan dan kondisi biofisik yang kurang menguntungkan menyebabkan mereka semakin sulit untuk bertahan. Kondisi tersebut tidak menyurutkan semangat mereka untuk bertahan hidup. Mereka adalah masyarakat mandiri ditengah keterasingan (Widodo, 2008; Rosyid, 2008), mereka bisa bertahan hidup karena mampu beradaptasi dengan kondisi lingkungannya. Menurut Berkes dan Folke (1998) masyarakat yang sering dihadapkan pada tantangan akan mempunyai banyak pengetahuan lokal dibanding masyarakat yang jarang menghadapi masa-masa kritis.

Studi etnoekologi merupakan bidang studi yang kehadirannya relatif baru, sehingga terminologinya masih menjadi perdebatan diantara para ahli. Paradigma baru tentang sustainability dalam ilmu ekologi mendorong munculnya bidang studi etnoekologi ini. Menurut Toledo (1992) bidang ilmu etnoekologi berkembang dari 4 bidang ilmu yaitu: etnobiologi, agro-ekologi, etnosain dan geografi lingkungan. Studi etnoekologi berkembang tidak hanya mempelajari interaksi antara suatu bentuk kehidupan dengan kehidupan lainnya, dan lingkungannya, tetapi bersifat menganalisis secara holistik sampai pada analisis tentang sistem pengetahuan masyarakat lokal dalam mengelola lingkungannnya berikut strategi adaptasi dan sistem produksi yang dikembangkan di lingkungannya tersebut (Purwanto, 2007).

Istilah etnoekologi dicetuskan oleh Harold Conklin pada tahun 1954 ketika mempelajari masyarakat Hanunoo di Philipina. Secara istilah Etnoekologi dapat didefinisikan sebagai suatu ilmu multi disiplin yang mengkaji hubungan timbal balik antara aspek pola pikir dan aspek praktis suatu etnik terhadap sumberdaya alam mereka berikut pengaruhnya dalam suatu proses produksi. Kajiannya bertumpu pada bagaimana pemanfaatan alam oleh kelompok masyarakat (ethnic) sesuai ragam kepercayaan, pengetahuan, tujuan dan bagaimana pandangan kelompok etnis bersangkutan dalam pemanfaatannya (Toledo, 1992).

Etnoekologi masyarakat lokal mencakup keseluruhan pengetahuan ekologi masyarakat lokal yang menganalisis semua aspek pengetahuan lokal masyarakat tentang lingkungannya meliputi persepsi dan konsepsi masyarakat lokal terhadap lingkungannya (corpus) beserta strategi adaptasi dan sistem produksi serta pengelolaan sumberdaya alam yang terdapat di dalamnya (praxis). Pengetahuan ini juga menganalisis pengaruh persepsi lokal tentang lingkungan serta pengaruh semua aktifitas manusia terhadap lingkungannya (Toledo, 1992; Purwanto, 2007).

Kearifan ekologi dalam konteks sejumlah pengetahuan yang berkaitan dengan kegiatan aktifitas masyarakat lokal dapat menggambarkan pola adaptasi yang memainkan peranan penting dalam keberhasilan pertanian mereka (Amsikan, 2006). Penggalian pengetahuan ekologi masyarakat lokal, khususnya di kalangan masyarakat Samin diharapkan mempunyai implikasi positif dan strategis terhadap pemeliharaan lingkungan dan sumberdaya alamnya untuk menunjang kelangsungan hidup mereka.

Tujuan penelitian ini adalah untuk mengungkapkan sistem pengetahuan lokal masyarakat Samin berkaitan interaksinya dengan lingkungan, antara lain meliputi: persepsi tentang alam semesta dan lingkungannya, pengetahuan tata ruang dan kekayaan hayati yang ada di dalamnya, pemanfaatan dan pengelolaannya; dan perubahan persepsi kepentingan lahan.

\section{BAHAN DAN METODE}

Penelitian dilakukan pada bulan Maret 2011 hingga Agustus 2011. Lokasi penelitian desa Larikrejo dan dan dusun Kaliyoso, desa Karangrowo, Kecamatan Undaan Kabupaten Kudus Jawa Tengah. Daerah tersebut dipilih 
karena (1) merupakan tempat tinggal/pemukiman masyarakat samin, (2) masih terdapat tokoh Samin (Botoh) yang mempunyai kemampuan lebih tentang ajaran Samin dan lingkungan alamnya, (3) Masyarakat Samin di dusun tersebut adalah masyarakat petani, yang masih mengandalkan sumberdaya alam dan lingkungan di sekitarnya untuk kehidupannya.

Alat dan bahan yang digunakan dalam penelitian ini antara lain: alat rekam, lembar kuesioner, alat tulis, kamera, peta lokasi, GPS; peralatan untuk analisis vegetasi: roll meter, tali untuk petak plot.

Penelitian dilakukan melalui empat tahap: (1). deskribsi serinci mungkin kondisi ekosistem; inventarisasi kekayaan hayati flora fauna di setiap unit lahan; (2) Menyusun kembali pola pikir (corpus) Masyarakat Samin mengenai persepsi dan konsepsi terhadap lingkungan dan sumber daya hayati di dalamnya, dengan metode survei partisipatif (Martin, 1996; Purwanto, 2007; Hendra, 2009), dan teknik wawancara (bebas open ended dan semi struktural (Grandstaff \& Grandstaff, 1987; Purwanto, 2007); (3) Mengkaji bentuk praktek pengelolaan sumberdaya alam hayati berikut teknologinya (praxis) (4) Untuk mengetahui perubahan persepsi kepentingan lahan dilakukan dengan pendekatan Focus Discussion Group (FDG), pengumpulan data dengan teknik Pebble Distribution Metdode (PDM)B (CIFOR 2004; Boissierre at al., 2009)

\section{HASIL DAN PEMBAHASAN Aspek Biofisik}

Kabupaten Kudus terletak diantara empat Kabupaten, sebelah utara berbatasan dengan Kabupaten Jepara dan Kabupaten Pati. Sebelah timur berbatasan dengan Kabupaten Pati, sebelah selatan berbatasan dengan Kabupaten Grobogan serta sebelah barat berbatasan dengan Kabupaten Demak dan Jepara. Letak Kabupaten Kudus antara $110^{0} 36^{\prime}$ dan $110^{\circ} 50^{\prime}$ Bujur timur dan antara $6^{0} 51^{\prime}$ dan $7^{\circ} 16^{\prime}$ Lintang Selatan.

Lokasi penelitian di Desa Larikrejo dan dusun Kaliyoso secara administratif termasuk dalam wilayah di Kecamatan Undaan. Topografi desa datar dengan kemiringan lahan $0-2^{0}$, desa tersebut semula merupakan rawa, sebagian lahan sawah sering tergenang air. Luas lahan 222,26 ha
(Larikrejo) dan 1.100,26 (Karangrowo), lahan sawah 61,71\% (Larikrejo) dan 81,75\% (Karangrowo). tegalan 32,17\% (Larikrejo) dan $13,58 \%$ (Karangrowo), serta sisa lahan berupa pekarangan $6,13 \%$ di Larikrejo dan 4,65\% di desa Karangrowo. Berada pada ketinggian rata-rata 50 $\mathrm{m}$ di atas permukaan laut. Jenis tanah umumnya alluvial coklat tua (BPS Kudus, 2010).

\section{Aspek Sosial budaya masyarakat Samin}

Masyarakat Samin di Kabupaten Kudus terutama bermukin di Desa Larikrejo dan Desa Karangrowo, Kecamatan Undaan, kurang lebih 10 $\mathrm{km}$ sebelah selatan Kota Kudus, atau $7 \mathrm{~km}$ dari Jalan Raya Kudus-Undaan. Perkampungan masyarakat Samin agak terpencil karena jauh dari jalan raya. Kondisi lahan pedesaan datar dengan areal persawahan yang masih luas.

Penganut Samin kedua desa tersebut berjumlah $70 \mathrm{KK}$, meliputi 240 jiwa. Mereka tinggal mengelompok dengan komunitasnya dan masih kuat memegang prinsip ajaran. Dalam hal pendidikan sebagian besar generasi tua tidak mengenyam pendidikan formal, sedangkan generasi mudanya sebagian besar sudah mengenyam pendidikan formal meskipun sedikit sekali yang sampai menamatkan SD. Mata pencaharian pencaharian utama mereka adalah petani, pekerjaan sampingan antara lain pencari ikan, tukang kayu atau tukang batu, atau buruh bangunan.

\section{Pandangan masyarakat tentang alam semesta}

Masyarakat Samin menyebut alam yang sedang kita tempati saat ini sebagai alam donya (alam dunia). Sedangkan alam yang akan ditempati nanti disebut alam kelanggengan. Alam dunia terdiri dari unsur- unsur tanah (lemah), air (banyu), api (geni) dan angin. Keempat unsur itu harus ada dalam keadaan seimbang, agar seimbang harus di tata. Mereka juga memahami adanya jagat gede dan jagad cilik. Alam raya atau alam semesta ini disebut sebagai jagad gede (makrokosmos). Bumi yang ditempati, langit dan matahari merupakan isi jagad gede. Sedangkan jagat cilik (mikrokosmos) adalah diri manusia sendiri. Dalam pandangan mereka jagad cilik dan jagad gede adalah sama. Jagad cilik itu merupakan gambaran dari jagat gede.

Dalam pandangan masyarakat bumi melambangkan nama perempuan, dari kata $i b u$ 
sing di mimi, dipundi-pundi, (ibu yang sangat dihormati) iso nukulke samubarang, senajan di idak-idak, dipaculi,dipiloro, tetep nguripi, ora nesu, ditanduri yo bakal woh, (bisa menumbuhkan berbagai macam tanaman, meskipun dinjak-injak, dicangkuli, disakiti, tidak marah, kalau ditanamami tetap memberikan hasil, tetap memberikan penghidupan). Bumi memberikan tempat perlindungan, menumbuhkan tanaman, menyediakan air, dan menyediakan segala kehidupan lainnya. Karena itulah masyarakat Samin sangat menghormati bumi. Penghormatan mereka terhadap bumi dengan bertani, mengolah tanah sebaik-baiknya, memberikan pupuk, menanami, merawat dan memberikan perhatian setiap hari. Ibarat merawat seorang ibu yang telah memberikan kasih sayang dan membesarkannya. Bumi ibarat ibu yang selalu dihormati.

Langit adalah nama atau simbol untuk laki-laki. Langit dan bumi merupakan suatu pasangan, langit sebagai laki-laki dan bumi sebagai perempuan. Langit berada di atas, dan bumi itu di bawah. Ini menjadi simbol bagi mereka bahwa laki-laki mempunyai kekuasaan yang lebih luas dibanding kaum wanita, namun laki laki juga mempunyai tugas lebih berat untuk melindungi dan menghidupi perempuan.

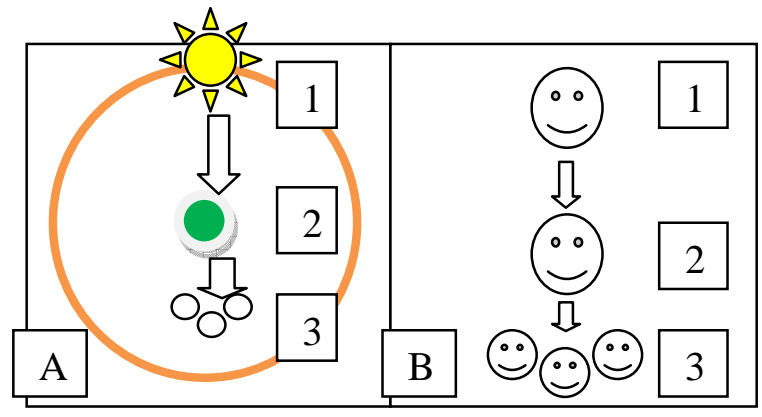

Gambar 1. Skema pandangan masyarakat Samin mengenai jagad gede dan jagad cilik. A. Jagad gede (alam semesta) (1) Langit dan matahari (2). bumi, (3) bibit kehidupan; B. Jagad cilik (diri manusia), diwujudkan dalam perkawinan masyarakat Samin, (1) suami/[emilik sawah (2) istri/sawah (3) generasi penerus.

Matahari dalam bahasa jawa adalah Srengenge, berasal dari kata sreng/ono karep (berarti hasrat atau keinginan). Matahari berada di atas, di langit, matahari melambangkan hasratnya atau energi. Matahari memancarkan energi, yang disalurkan ke bumi, bumi menyimpan benih kehidupan. Adanya sinergi antara bumi dan matahari menciptakan kehidupan di bumi. Kehidupan dibumi dapat terus berlangsung karena adanya sinergi antara unsur bumi yang diserab tumbuhan yang mampu secara langsung memanfaatkan energi matahari dalam proses fotosintesis sehingga dihasilkan bahan-bahan organik yang diperlukan untuk bahan pangan organisme lainnya.

Masyarakat Samin merealisasikan pandangan mengenai perkawinan antara langit dan bumi tersebut dalam bentuk perkawinan antara laki-laki dan perempuan (sikep rabi). Perkawinan merupakan merupakan jalan yang mulia untuk menghasilkan keturunan guna melanjutkan kehidupan berikutnya. Dalam ajaran Samin untuk menciptakan kehidupan atau keturunan yang baik, harus di awali dengan tata cara perkawinan dengan tata cara sikep rabi (pernikahan cara masyarakat Samin). Pernikahan adalah sesuatu yang sakral, untuk menebarkan benih kehidupan dengan cara yang baik, agar di hasilkan keturunan yang baik pula. Dengan generasi yang baik diharapkan akan dihasilkan kualitas kehidupan yang lebih baik.

\section{Pandangan masyarakat terhadap manusia dan lingkungan}

Pandangan masyarakat samin terhadap lingkungannya tidak terlepas dari ajaran atau falsafah hidupnya. Pola pikir mereka sederhana, tindakan mereka sesuai dengan pikiran dan ucapannya, antara lahir dan batin sama. Kata Samin dapat diartikan sami-sami, sama-sama, atau tidak berbeda dengan lainya. Masyarakat Samin tidak pernah menganggap mempunyai derajat yang lebih tinggi dari masyarakat lainnya, dalam arti setiap manusia adalah sama, sesama hidup, sama derajatnya, bahkan dengan makhluk hidup lainnya. 


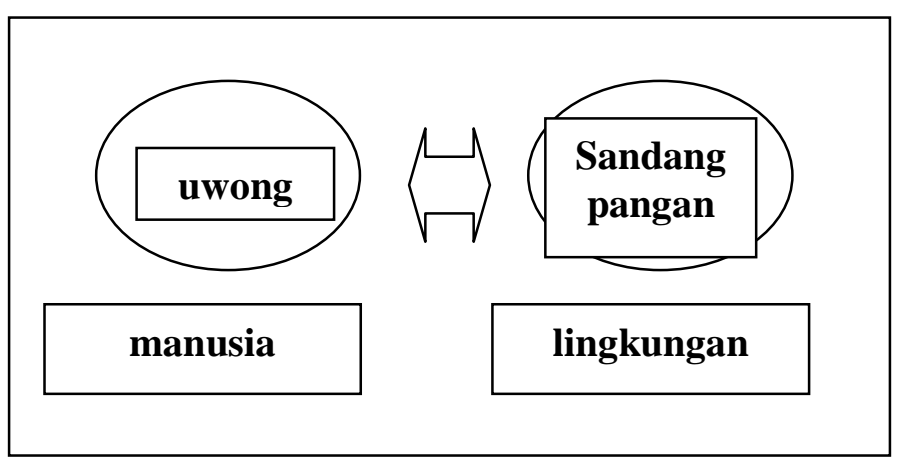

Gambar 2. Skema pandangan Masyarakat Samin mengenai manusia dan lingkungan

Masyarakat Samin membagi isi dunia ini dalam dua bentuk yaitu wong (manusia/hidup) dan sandang pangan (penghidupan). Wong, dimaknai sebagai manusia atau diri kita ini yang diberi hidup diamanahi sebagai pengelola kehidupan dibumi. Sedangkan sandang pangan, merupakan kelengkapan atau sumber penghidupan di bumi. Segala sesuatu yang bukan manusia itu disebut sebagai sandang pangan. Dalam pemahaman keilmuan sekarang, konsep tersebut dapat diibaratkan sebagai manusia dan lingkungannya, atau antara sistem sosial dan sistem biofisik (Rambo, 1985).

\section{Pandangan tentang makhluk hidup}

Masyarakat Samin menyebut manusia, hewan dan tumbuhan, sebagai 'tri tunggal' (satu wujud yaitu hidup, dalam tiga bentuk yakni manusia, hewan dan tumbuhan). Wujud hidup yang pertama adalah manusia dan kedua adalah sandang pangan. Sandang pangan yang hidup dapat dibedakan menjadi sandang pangan yang hidup dan bisa berjalan, bergerak, atau berpindah tempat, wujudnya adalah hewan, dan kedua sandang pangan yang hidup tapi tidak dapat berjalan atau berpindah tempat wujudnya adalah tumbuhan.

Manusia, hewan dan tumbuhan mempunyai satu kesamaan yaitu hidup. Makhluk tersebut kedudukannya sama, sama-sama hidup. Bentuk konkrit dari ajaran ini adalah mereka menghormati hak hidup bagi makhluk sesama, seperti tidak membunuh atau merusak sesama hidup, menyediakan tempat hidup, memberikan pangan, tidak menggangap binatang pengganggu atau hama seperti tikus, wereng, walang sangit sebagai 'musuh' tetapi dipahami bahwa hewan tersebut seperti manusia butuh makan untuk kelangsungan hidupnya.

\section{Pandangan tentang Rumah}

Masyarakat samin menyebut rumah sebagai mondokan, karena pada tempat itulah yang menjadi tempat mondoknya seluruh anggota keluarga dan tempat mondoknya sandang pangan. Berbeda dengan pemahaman masyarakat Jawa, yang biasa menyebut rumah dengan nama omah. Dalam pemahaman masyarakat Samin yang dimaksud omah adalah awak atau badan manusia. Awak iku omahing urip (badan itu yang ketempatan hidup). Hidup di sini dapat diartikan ruh atau nyawa. Karena itu mereka menyebut rumah bukan dengan istilah omah, tapi dengan istilah mondokan.

Mondokan, rumah atau tempat tinggal sebagaimana masyarakat lainnya mempunyai fungsi sebagai tempat berlindung bagi setiap anggota keluarga, tempat melaksanakan berbagai aktifitas rumah tangga, melangsungkan keturunan, membesarkan keturunan, tempat mewariskan ajaran atau norma-norma kehidupan, memasak, beristirahat, bercengkerama dan sebagainya.

Dalam konsep masyarakat Samin mondokan atau rumah juga merupakan 'sekolah' tempat untuk menyampaikan ajaran, atau norma-norma untuk kehidupan yang baik. Guru yang utama adalah orang tua masing masing. Orangtualah yang mempunyai kewajiban utama mendidik keturunan mereka menjadi orang yang berkelakuan baik, hingga bisa bekerja dan hidup mandiri. Sehingga keberadaan sekolah formal tidak wajib bagi mereka. Saat ini sekolah formal yang dijalani oleh generasi mudanya lebih bertujuan untuk bisa membaca dan menulis, tidak untuk mendapatkan ijasah untuk mencari pekerjaan.

\section{Pandangan tentang lahan pertanian}

Lahan pertanian bagi masyarakat Samin disebut sebagai lemah garapan. Lemah garapan adalah lahan yang digunakan untuk aktifitas budidaya pertanian yang merupakan pekerjaan sehari hari. Bagi masyarakat samin lemah garapan merunjuk kepada tanah sawah. Namun dalam pemahaman yang lebih luas lemah penggarapan ini dibedakan menjadi lemah teles (sawah) dan 
lemah garing (kebon, tegalan, termasuk alas atau hutan).

Sawah, menurut pandangan masyarakat samin kata 'sawah' berarti istri, sedang laki-laki adalah 'pemilik sawah'. Pekerjaan utama mereka adalah sebagai petani mengolah tanah dan menanaminya hingga mendapatkan hasil untuk memenuhi kebutuhan hidup mereka. Pekerjaan sebagai petani dijalankan sebagai manivestasi bentuk 'interaksi' antara 'sawah' dan 'pemilik sawah' antara istri dan suami. Karena itu mereka menganggap menjadi petani adalah pekerjaan yang mulia, maka dijalaninya dengan sepenuh jiwa.

\section{Pengetahuan tentang kesuburan tanah}

Kesuburan tanah tergantung ada atau tidaknya usaha manusia mengolahnya. Seperti dalam ungkapan mereka "Subur lan orane lemah $i k u$ gumantung wonge, yen lemah dipaculi yo subur, yen ora tau dipaculi yo dadi ora subur" (Subur atau tidaknya tanah itu ditentukan oleh orangnya, kalau tanah dicangkuli, dirawat dengan baik, maka tanah menjadi subur, tetapi kalau tidak dicangkuli tidak diolah dengan baik maka tanah akan menjadi tidak subur). Pemahaman ini menunjukkan bahwa masyarakat Samin merupakan petani yang ulet dan bekerja keras untuk bisa mendapatkan hasil yang baik.

Tanah yang subur biasanya berwarna merah kebiruan (abang biru), bila kering ngropyok (gembur, mudah lepas). Sedang tanah yang tidak subur (lemah gering), bila kering mengkel (keras). Tanah yang cukup air biasanya subur, bila diberi pupuk mudah diserab tanaman. Pada tanah ledokan (tempat lebih rendah) biasanya lebih subur karena mendapat aliran air yang mengandung pupuk dari tempat yang lebih tinggi (nggeneng). Tanah kering biasanya kurang subur, bila dipupuk tidak ada air, pupuk tidak bisa langsung diserab tanaman.

\section{Pengetahuan tentang tata ruang}

Masyarakat Samin di Kudus mengenali satuan lingkungan di sekitar pemukiman mereka berdasarkan bentuk dan fungsinya. Pemahaman tentang bentuk dan fungsi satuan lahan tersebut terwujud dalam berbagai aktifitas yang dijalani keseharian. Satuan lingkungan mereka berupa pekarangan, tegalan, sawah, sungai, dan rawa..

Tabel 1. Satuan lingkungan pada Masyarakat Samin di Kudus

\begin{tabular}{|c|c|c|c|}
\hline No & $\begin{array}{l}\text { Satuan } \\
\text { lingkungan }\end{array}$ & Fungsi & Kekayaan Hayati \\
\hline 1 & Rumah & $\begin{array}{l}\text { Fungsi sosial budaya } \\
\text { (Tempat tinggal, interaksi } \\
\text { sosial, pendidikan) }\end{array}$ & \\
\hline 2 & Pekarangan & $\begin{array}{l}\text { Fungsi sosial budaya } \\
\text { Fungsi ekonomi subsisten ( } \\
\text { lahan budidaya untuk } \\
\text { kebutuhan sendiri) } \\
\text { Fungsi ekologi (Peneduh, } \\
\text { plasma nutfah) }\end{array}$ & $\begin{array}{l}\text { Kekayaan hayati dominan adalah Jenis tanaman } \\
\text { budidaya, terutama jenis buah, sayur dan bumbu, } \\
\text { tanaman obat, dan tanaman kayu bakar dan bangunan. } \\
\text { Jenis pohon dominan adalah Pring ori (Bambusa } \\
\text { bambos), Pisang (Musa paradisiaca, kultivar ambon, } \\
\text { kepok, susu), mangga (mangifera Indica) dan Meh } \\
\text { (Samanea saman). Jenis semak terutama didominasi } \\
\text { tumbuhan meliar seperti sabrang (Ipomoea } \\
\text { crasicaulis) dan Trembelutan (Phyllantus reticulatus) }\end{array}$ \\
\hline 3 & Tegalan & $\begin{array}{l}\text { Fungsi ekonomi subsisten } \\
\text { (Kebutuhan sendiri) } \\
\text { Fungsi ekologi (Penguat } \\
\text { tanggul, plasma nutfah) }\end{array}$ & $\begin{array}{l}\text { Lahan berupa tanggul, bantaran sungai, tidak dikelola } \\
\text { intensif, jenis dominan adalah tumbuhan untuk kayu } \\
\text { Bakar al: Meh (Samanea saman) dan lamtoro } \\
\text { (Leucaena glauca), serta tanaman buah terutama } \\
\text { Pisang (Musa paradisiaca). }\end{array}$ \\
\hline 4 & Sawah & $\begin{array}{l}\text { Fungsi ekonomi (Sumber } \\
\text { penghasilan utama) }\end{array}$ & $\begin{array}{l}\text { Lahan sawah ber-irigasi, dikelola intensif, pola tanam } \\
\text { padi-padi-palawija. Jenis padi varietas unggul IR } 64 \text {, } \\
\text { Ciherang. Palawija : buah semangka biji , semangka } \\
\text { buah, blewah. }\end{array}$ \\
\hline
\end{tabular}




\begin{tabular}{|c|c|c|c|}
\hline 5 & Rawa & $\begin{array}{l}\text { Fungsi ekologi (reservoar, } \\
\text { plasma nutfah) } \\
\text { dan ekonomi (pakan ternak, } \\
\text { sumber pangan ikan) }\end{array}$ & $\begin{array}{l}\text { Jenis tumbuhan dominan terutama tanaman } \\
\text { kangkung air (Ipomoea aquea) untuk pakan ternak, } \\
\text { dan terate (Nympaeae). Jenis ikan ikan seperti, lele } \\
\text { rawa, bethik (Ananas testudinetus), sepat } \\
\text { (Trichogaster trichopterus), wader (Rasbora } \\
\text { argineteria). }\end{array}$ \\
\hline 6 & Embung & $\begin{array}{l}\text { Fungsi ekologi (Reservoar), } \\
\text { Fungsi ekonomi (budidaya } \\
\text { ikan dan sumber ikan liar) }\end{array}$ & $\begin{array}{l}\text { Jenis ikan yang biasa di temukan antara lain: Lundu/ } \\
\text { Kuthuk (Chana striata), Bloso, lele rawa, udang, } \\
\text { Mujair (Oreochromis mossambicus), nila, bethik, ikan } \\
\text { sapu-sapu. }\end{array}$ \\
\hline 7 & Sungai & $\begin{array}{l}\text { Fungsi ekologi (Sumber } \\
\text { pengairan sawah) } \\
\text { Fungsi ekonomi (Sumber } \\
\text { ikan) }\end{array}$ & $\begin{array}{l}\text { Jenis ikan banyak berkurang karena, pencarian ikan } \\
\text { dengan racun atau dengan setrum. Jenis ikan yang ada } \\
\text { al: Bethik, sepat, lele, kutuk, bloso }\end{array}$ \\
\hline
\end{tabular}

\section{Pengelolaan lingkungan}

Masyarakat Samin telah melaksanakan praktek mengelola lingkungan secara turun temurun. Praktek ekologi yang menggambarkan keterkaitan antara manusia dan lingkungannya telah lama di miliki oleh masyarakat tempaan (Walujo, 2009). Mereka telah membagi dan mengelola berbagai satuan lingkungan yang ada di sekitar berdasarkan fungsinya untuk mempertahkan kehidupan mereka. Bagi Masyarakat Samin sawah merupakan satu-satunya lahan yang dikelola secara intensif. Sistem pertanian telah berkembang mengikuti sistem pertanian modern yang seperti masyarakat umum lainnya. Penggunaan traktor, bibit unggul, pupuk kimia, dan bahan pestisida sudah menjadi budaya dalam sistem pertanian masyarakat Samin. Hal ini menunjukkan bahwa mereka terbuka dengan kemajuan pengetahuan dan teknologi.

Satuan lahan lain seperti tegalan dan pekarangan tidak dikelola secara intensif. Lahan dibiarkan apa adanya tanpa pengolahan tanah, pemupukan, atau perawatan khusus. Tumbuhan yang ada di pekarangan atau tegalan biasanya dibiarkan tumbuh meliar tanpa perawatan intensif. Vegetasi dipekarangan lebih berfungsi secara ekologis untuk kenyamanan di banding fungsi ekomonisnya. Rawa merupakan lahan alami, yang keberadaannya makin berkurang, tanpa ada pengelolaan khusus. Embung, sungai, merupakan lahan semi alami yang yang bernilai secara ekologi dan ekonomi yang belum dimanfaatan dan dikelola secara optimal.

\section{Kearifan lokal dalam mengelola lahan sawah}

Dalam praktek pertanian meskipun sudah menggunakan cara modern, dalam beberapa hal masih menyimpan kearifan lokal. Terutama berkaitan dengan bagaimana mereka menanamkan rasa bangga menjadi petani. Masyarakat

Samin adalah bagian dari masyarakat Jawa, yang masih mempunyai kebanggaan yang tinggi berprofesi sebagai petani. Hal ini dilakukan karena bertani merupakan pelaksanaan keyakinan mereka. Bertani adalah pekerjaan mulia untuk melanjutkan misi kehidupan di bumi. Bertani dengan 'jiwa' merupakan karakter masyarakat Samin yang, sudah tidak banyak ditemukan pada masyarakat Jawa pada umumnya.

Bentuk kearifan lainnya antara lain dapat diamati dalam praktek pengelolaan tanah, memaknai kesuburan tanah, penyiapan benih, penanggulangan terhadap hama dan mengelolaan panen. Penyiapan bibit padi (wineh), merupakan tahap yang penting. Jenis yang digunakan adalah varitas padi unggul tetapi mereka membuat sendiri benih padi yang akan di tanam. Kriteria memilih padi yang baik untuk bibit, antara lain: (1) pari mapak, tanaman padi yang akan diambil untuk bibit mempunyai ketinggian sama/rata, sehingga akan dihasilkan bibit yang seragam. (2) Ulen landing , tangkai padi panjang. (3) dapuran/anakan padi lebih besar, berarti tanaman subur.

Dalam menanggulangi tanaman terhadap seranggan hama Masyarakat Samin memiliki mempunyai kearifan tersendiri, mereka menggunakan "cara halus". Dengan memahami bahwa hewan yang dianggap hama tersebut 
sebenarnya tidak bermaksud mengganggu atau merusak tanaman manusia, tetapi karena "butuh urip lan butuh mangan" (hidup butuh makan). Sebagai sesama hidup manusia tidak mempunyai hak untuk membunuhnya. Cara menanggulanginya adalah dengan menyediakan apa yang mereka butuhkan (sajen). Bentuk makanan yang disiapkan adalah apa yang diperoleh dari hasil 'perenungan' mereka. Pemberian makanan tersebut disertai permohonan secara gaib, agar hama tersebut tidak mendatangi tanaman penduduk lagi.

Dalam pengelola hasil panen berlaku tradisi pembagian hasil. Hasil panen dibagi untuk empat keperluan yakni: untuk wineh, untuk sandang, untuk pangan dan untuk bawon. Bagian untuk wineh (bibit) selalu disiapkan untuk musim tanam berikutnya. Bagian yang untuk sandang adalah yang untuk kebutuhan sehari hari selain untuk makan, misalnya untuk membeli pupuk, untuk keperluan sosial dan keperluan rumah tangga lainnya. Bagian yang untuk pangan untuk kebutuhan pakan/makan keluarga. Bagian terakhir bawon adalah bagian untuk yang membantu pemanenan padi.

Masyarakat Samin jarang mengalami krisis pangan karena mereka selalu mempunyai persediaan pangan. Mereka mempunyai strategi untuk bisa bertahan hidup dengan sumberdaya yang ada dengan menyimpan sebagian hasil. Simpanan dari hasil panen masa tanam pertama sekitar 17-20 sak (sekitar 6kwintal). Sedangkan setelah hasil panen musim kedua simpanan lebih banyak, 27-30 sak (sekitar 10kwintal) untuk persiapan selama musim kemarau.

\section{Perubahan pandangan tentang kepentingan} lahan bagi masyarakat

.Pandangan mereka mengenai kepentingan lahan tersebut bagi aktivitas keseharian mereka sedikit banyak mengalami perubahan terkait dengan kondisi biofisik maupun kondisi sistem sosial di lingkungan mereka. Berdasarkan hasil Focus Discussion Group (FDG), yang dilakukan terhadap sejumlah masyarakat Samin, dan mereka di minta untuk memberikan skor dengan metode 'kerikil' PDM (Pebble Distribition Method) untuk menilai kepentingan lahan secara relatif bagi aktivitas keseharian Masyarakat Samin, diperoleh hasil seperti ditampilkan pada gambar 3

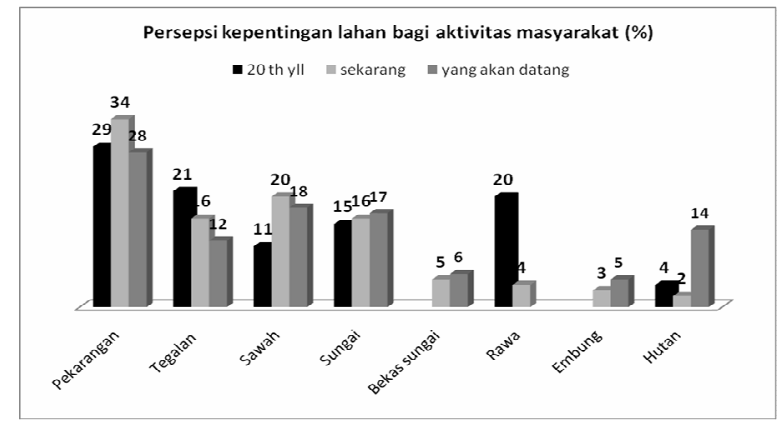

Gambar 3. Perubahan pandangan terhadap kepentingan lahan bagi aktivitas masyarakat

Berdasarkan diagram tersebut diketahui bahwa lahan pekarangan merupakan lahan yang paling penting dalam aktivitas keseharian mereka karena di pekarangan tersebut terdapat rumah atau tempat tinggal yang merupakan ruang utama dalam aktivitas keseharian mereka. Rumah yang menyatu dengan pekarangan mempunyai fungsi sosial yang paling penting dalam pandangan masyarakat samin. Selain itu pekarangan juga mempunyai fungsi ekonomi dan fungsi ekologi sebagai tempat budidaya berbagai jenis tanaman.

Perubahan yang paling mencolok adalah perubahan kepentingan lahan rawa, sekitar 20 tahun yang lalau, rawa mempunyai nilai penting yang cukup tinggi, karena pada saat itu lahan rawa paling luas dan kaya dengan berbagai jenis ikan, mata pencarian utama mereka saat itu adalah mencari ikan. Sekarang lahan rawa dianggap kurang penting, karena sebagian besar lahannya sudah berubah menjadi sawah. Sebaliknya peran lahan sawah, meningkat dari waktu ke waktu, sekarang sawah merupakan lahan utama masyarakat samin untuk menopang kehidupannya sebagai petani.

Kepentingan lahan tegalan dulu dan sekarang mengalami perubahan, dulu tegalan sangat penting karena merupakan lahan utama untuk mencari pakan ternak, tetapi karena sekarang jarang yang mempunyai ternak besar (sapi), maka nilai kepentingan berkurang, demikian juga untuk kepentingan ke depan.

Masyarakat Samin cukup terbuka dan mempunyai pengetahuan yang memadai tentang konservasi lingkungan. Hal ini tergambar dari pandangan mereka tentang hutan. Lahan hutan 
sebenarnya merupakan lahan yang letaknya jauh dari pemukiman mereka, jaraknya sekitar 5-7 km. Masyarakat samin di Kudus menganggap bahwa keberadaan hutan di masa yang akan penting, dan harapan kondisi hutan bisa lebih baik, sehingga kecukupan dan ketersediaan air untuk kegiatan pertanian mereka tetap terjaga. Pandangan ini mengisyaratkan bahwa masyarakat samin mempunyai pangangan yang jauh kedepan, bahwa lingkungan harus tetap terjaga, demi kehidupan.

\section{KESIMPULAN}

Masyarakat Samin Kudus mempunyai pemahaman yang baik terhadap lingkungannya. Pengetahuan tradisional tentang lingkungannya tergambar pada bentuk penggunaan lahan dan sistem pengelolaannya. Unit lahan bagi aktifitas produksi mereka berupa sawah, pekarangan, tegalan, rawa, dan embung, sungai. Sawah merupakan lahan yang dikelola secara intensif, pekarangan tegalan tidak dikelola dengan intensif. Masyarakat Samin masih mempunyai kearifan lokal dalam mengelola lingkungannya. Interaksi antara masyarakat Samin dengan lingkungannya dipengaruhi oleh pandangan hidupnya, ibarat manusia dengan sandang pangan, atau ibarat hidup dengan yang memberi penghidupan. Pandangan tentang kepentingan lahan bagi aktivitas masyarakat mengalami perubahan seiring dengan perubahan kondisi biofisik lingkungan dan tingkat pengetahuan masyarakat.

\section{DAFTAR PUSTAKA}

Amsikan, Y.G. 2006. Manfaat Kearifan ekologi Terhadap pelestarian lingkungan. Suatu studi etnoekologi di Kalangan Orang Biboki. AKADEMIKA, Jurnal Kebudayaan Vol.4. No.1 April 2006.

Berkes,F. dan Folke, C, 1998. Linking Social and Ecological System for Resilience and Sustainability dalam Berkes and Folke, C.(Ed.) Linking Social and Ecological System: Management Practices and Spcial Mechanism for Buiding Resiliencies. Cambride University Press, hal 1-25
BPS Kudus, 2010. Kecamatan Undaan dalam angka. BPS Kabupaten Kudus

Boissiere, M, Padmanaba, M. Liswanti N., Sheil D., Basuki I., van Heis M., Wan, M. 2009. Multidisplinary Landscape Assesment (MLA): Mengekplorasi Keanekaragaman Hayati, Lingkungan dan Pandangan masyarakat Lokal mengenai lanskap hutan. Dalam Purwanto, Y. dan Walujo, E (Ed.). Keanekaragaman Hayati, Budaya dan Ilmu Pengetahuan, Prosiding Seminar Nasional Etnobotani IV. LIPI Press, Jakarta hal 33-41

CIFOR. 2004. Mengekploitasi keanekaragaman hayati, lingkungan dan pandangan masyarakat lokal mengenai berbagai lanskap hutan. Metode-metode penilaian lanskap secara multidisipliner. Cifor, Bogor, Indonesia

Conklin, H.C.1954. An Etnoecologycal Approach to Shifting Agricuture. Dalam Transaction of the New York of Academy of Science II, (17): 133-142

Grandstaff, SW \& Grandstaff TB. 1987. Semi Structure Interviewing by Multidicipline Teams in RRA. KKU Prociding : $69-88$.

Hendra, M. 2009. Etnoekologi Perladangan dan Kearifan Botani Lokal masyarakat Dayak Benuaq di Kabupaten kutai Barat Kalimantan Timur. Disertasi Sekolah Pascasarjana IPB (Tidak dipublikasikan)

Hutterer K \& Rambo AT. 1985. Introduction dalam In Cultural values and human ecology in Southeast Asia. Hutterer KL, Rambo AT \& Lovelace G (eds). Michigan: Michigan Paper on Southeas Asia Center for South and Southeast Asian studies The University of Michigan

Marten GG. 2001. Human Ecology. Basic Consept for Sustainable Development. Earthscan Publication Ltd, London

Martin, G.J., 1996. Etnobotani. Chapman and Hall, London

Parson, JR., 1982. Primitive Polluters. Semang Impac on The Malaysian Tropoical Rain Forest Ecosystem. Anthro[poplogical Papers. Museum Anthropologi, University of Michigan. No 76.

Purwanto Y. 2007. Ethnobiologi. Ilmu interdisipliner, metodologi, aplikasi, dan 
prosedurnya dalam pengembangan Sumberdaya tumbuhan. Bahan Kuliah PascaSarjana IPB(inpress)

Rambo T.A.1983. Conceptual Approach to Human Ecology. Research Report No.14. East West Environment and Institute, Honolulu Hawai

Rosyid M. 2008. Samin Kudus: Bersahaja di Tengah Asketisme Lokal. Penerbit Pustaka Pelajar Yogyakarta

Toledo V.M. 1992. What is etnoekologi ? Origin, scop and implications of arising discipline. ETNOECOLOGI. Vol I. No.1. April 1992.
Walujo, E.B. 2009. Etnobotani, Menfasilitasi penghayatan, pemutakhiran pengetahuan dan kearifan lokal dengan menggunakan prinsip-prinsip dasar ilmu pengetahuan. Dalam Purwanto, Y dan Eko Baroto Walujo (Ed). Keanekaragaman Hayat, Budaya dan ilmu Pengetahuan. Seminar Etnobotani IV/ Penerbit LIPI Press, Jakarta

Widodo S. 2008. Masyarakat Samin di tengah Arus Modernisasi. (http://learningof.slametwidodo.com/2008/02/01/, 24 Desember 2008) 